\title{
SELF-EMULSIFYING DRUG DELIVERY SYSTEMS: A REVIEW
}

\author{
Jamilur Reza* \\ Department of Pharmacy \\ University of Science and Technology Chittagong
}

\begin{abstract}
Self-emulsifying drug delivery systems (SEDDS) possess unparalleled potential in improving oral bioavailability of poorly water-soluble or lipophilic drugs. Following their oral administration, these systems rapidly disperse in gastrointestinal fluids, yielding micro- or nanoemulsions containing the solubilized drug. Owing to its miniscule globule size, the micro/nanoemulsified drug can easily be absorbed through lymphatic pathways, bypassing the hepatic first-pass effect. But it has drawbacks as formulation development, quality control, stability etc. These liquid SEDDS can be converted into solid dosage form without affecting drug release property. After administering the drug gets released and self emulsify in the GI tract. Generally solid SEDDS are formed with mono, di or triglycrides of fatty acid, non ionic surfactants and solidifying agents with diluents such as microcrystalline cellulose, lactose etc.
\end{abstract}

Keywords: Self-emulsifying drug delivery systems (SEDDS), drug delivery

\section{Introduction}

The oral route is one of the preferred routes for chronic drug therapy. Approximately $35-40 \%$ of new drug candidates have poor water solubility. The oral delivery of such drugs is frequently associated with low bioavailability, high inter and intra subject variability and lack of dose proportionality. Efforts are going on to enhance the oral bioavailability of lipophilic drugs in order to increase their clinical efficacy. To overcome these problems, new strategies were reported to increase solubility and bioavailability including complexation with cyclodextrins, solid dispersation (suspension), co-precipitation, micronisation, salt formation, emulsion, use of micelles, and cogrinding. ${ }^{1.4}$ Emulsions are used as vehicles for the administration of drugs, especially due to its potential of enhancing the oral bioavailability of poorly absorbed drugs. ${ }^{5}$ Microemulsions has got advantage like excellent thermodynamic stability, high drug solubilization capacity, improvement in oral bioavailabity and protection against enzymatic hydrolysis. The only problem with microemulsion is poor palatability due to the lipid content leading to poor patient compliance, more over due to their water content, microemulsions cannot be encapsulated into soft gelatin or hard gelatin capsule. There is a need for converting it into an alternative formulation like anhydrous self emulsifying drug delivery system (SEDDS) etc., because of its low loading dose. ${ }^{6}$

${ }^{*}$ Correspondence to Author:

r.jamilur@yahoo.com 
SEDDS are solid dosage form with a unique property, that is they are able to self emulsify rapidly into fine $\mathrm{O} / \mathrm{W}$ emulsion in the gastrointestinal fluids, under gentle agitation provided by the gastrointestinal tract. This fine O/W emulsion results in small droplets of oil dispersed in the gastrointestinal fluids that provide a large interfacial area enhancing the activity and minimizing the irritation due to contact of drug in the gut wall. ${ }^{5,70}$ Self Emulsifying System (SES) can be formulated with little energy input and the shelf life is longer than conventional emulsions.

\section{Purpose}

1. Highly important consideration in the formulation of solid SES is effective incorporation of the drug, in terms of both the solubilization within the oil surfactant mix in order to allow a suitable solid dosage to form and once formed the effect that the drug may have on the emulsification properties.

2. The advantage of solid SES is in its dose reduction, if an improvement in oral bioavailability is established.

\section{Mechanism of Self-Emulsification}

The mechanism, by virtue of which self-emulsification tends to occur has not yet been thoroughly elucidated. Nevertheless, it has been suggested that self-emulsification takes place when the entropy change favoring dispersion is greater than the energy required to increase the surface area of the dispersion. ${ }^{11,12}$ The free energy of a conventional emulsion formulation is a direct function of the energy required to create a new surface between the oil and water phases. The thermodynamic relationship for the net free energy change is described by Equation 1.

$$
\Delta G=\sum N_{i} 4 \pi r_{i}^{2} \sigma
$$

where, $\Delta G$ is the free energy associated with the process, $r_{i}$ is the radius of droplets, $\mathrm{Ni}$ is the number of droplets, $\sigma$ is the interfacial energy. The two phases of the emulsion tend to separate with time to reduce the interfacial area and thus, minimize the free energy of the system(s). The conventional emulsifying agents stabilize emulsions resulting from aqueous dilution by forming a monolayer around the emulsion droplets, reducing the interfacial energy and forming a barrier to coalescence. On the other hand, emulsification occurs spontaneously with SEDDS, as the free energy required to form the emulsion is low, whether positive or negative. ${ }^{13}$ For emulsification to take place, it is vital for the interfacial structure to offer negligible or no resistance against surface shearing. ${ }^{14}$ The ease of emulsification has been suggested to be related to the ease of water penetration into various liquid crystals or gel phases formed on the surface of the droplet. ${ }^{15,16}$ The interface between the oil and aqueous continuous phases is formed upon addition of a binary mixture (oil/non-ionic surfactant) to water. ${ }^{15}$ This is followed by solubilization within the oil phase, as a result of aqueous penetration through the interface. Invariably, this tends to occur until the 
solubilization limit is attained close to the interphase. Further, aqueous penetration will lead to the formation of the dispersed liquid crystal phase. Ultimately, everything that is in close proximity with the interface will be liquid crystal, the actual amount of which depends upon the emulsifier concentration in the binary mixture. Hence, following gentle agitation of the self-emulsifying system, water rapidly penetrates into the aqueous cores leading to interface disruption and droplet formation.

As a result of the liquid crystal interface formation surrounding the oil droplets, the SEDDS become quite stable to coalescence. Moreover, the presence of the drug compound may alter the emulsion characteristics, possibly by interacting with the liquid crystal phase. Nevertheless, the correlation between the liquid crystal formation and spontaneous emulsification has still not been properly established. ${ }^{17}$

\section{Technique of solid SEDDS development}

Solid SEDDS were developed mainly by adsorption of solid carriers, spray drying, melt extrusion, dry emulsion, solid dispersion etc. These solid SEDDS can be converted into pellets, tablets and capsules.

\section{Solid carriers}

These solid carriers have property to absorb liquid/semisolid formulation as self emulsifying system (SES). It is a simple procedure, where SES is incorporated into a free flowing powder material which has adsorption quality. The mixture is uniformly adsorbed by mixing in a blender. This solid mixture is filled into capsule or added to more excipient before compression into tablets. ${ }^{18}$ The above mixture was solidified to powder forms using three kinds of adsorbents: microporous calcium silicate (FloriteTM RE); magnesium aluminum silicate (NeusilinTMUS2) and silicon dioxide (SylysiaTM 320). ${ }^{19}$

\section{Spray Drying}

In this technique first the prepared formulation containing oil, surfactant, drug, solid carrier etc, is sprayed into a drying chamber through a nozzle. The volatile vehicles first evaporate leaving behind small solid particles. These particles are then filled into capsules or compressed into tablets.

\section{Melt extrusion}

This formulation technique depends on the property of the plastic mass material which can be easily extruded and speronised with pressure. Here there is no need for addition of liquid form of excipient but a constant temperature and pressure need to be maintained. ${ }^{20}$

\section{Dry Emulsion}

It is mainly $\mathrm{O} / \mathrm{W}$ emulsion, which is then converted into solid form by spray drying/solid carrier/ freeze drying. ${ }^{21}$ 


\section{Conclusion}

Self emulsifying drug delivery system in solid dosage form has improved solubility/dissolution, absorption and bioavailability for poorly water soluble drug. This is the method suited for lipophilic drugs where resulting emulsification gives faster dissolution rates and absorption. Solid SEDDS is superior to SEDDS in reducing production cost, simplifying industrial manufacture, and improving stability as well as patient compliance. Solid SEDDS has the flexibility to develop into different solid dosage form for oral and parenteral administrations.

\section{References}

1. York $P$, The design of dosage forms, In: Aulton M.E. (eds.), Pharmaceutics The science of dosage form design. Churchill Livingstone, Edinburgh; 1988. p 1-13.

2. Sugimoto M, Okagaki T, Narisawa S, Koida $\mathrm{Y}$, and Nakajima K. Improvement of dissolution characteristics and bioavailability of poorly water-soluble drugs by novel cogrinding method using water-soluble polymer. Int. J. Pharma, 1998; 160: 11-19.

3. Perng $\mathrm{CH}$, Kearney AS, Patel K, Palepu NR, Zuber G. Investigation of formulation approaches to improve the dissolution of SB-210661, a poorly water soluble 5lipooxygenase inhibitor. Int. J. Pharma, 1998; 176: 31-38.

4. Nazzal S, Guven N, Reddy IK, Khan MA. Preparation and characterization of Coenzyme Q10 - Eudragit solid dispersation. Drug Dev. Ind. Pharm. 2002; 28: 49-57.

5. Pouton CW, Self-emulsifying drug delivery system; assessment of the efficiency of emulsification. Int. J. Pharm. 1985; 27: 335-348.

6. Patravale VB, Date AA, Kale AA. Oral self micro emulsifying system: potential in drug delivery system. Pharma Technology Express Pharma Pulse special feature, 2003; 29: 44-48.

7. O'Driscoll CM. Lipid based formulation for intestinal lymphatic delivery. Eur. J. Pharm. Sci. 2002; 15: 405-415.

8. Charman SA, Charman WN, Rogge MC, Wilson TD, Dutko FJ, Pouton C W. Selfemulsifying drug delivery system: formulation and biopharmaceutical evaluation of an investigational lipophilic compound. Pharm. Res. 1992; 9: 87-93.

9. Shah NH, Carvajal M T, Patel Cl, Infiled M H, Malick AW. Selfemulsifying Drug Delivery systems (SEDDS) with polyglycolized glycerides for improving in-vitro dissolution and oral absorption of lipophilic drugs. Int. J. Pharm. 1994; 106: 15-23.

10. Khoo S M, Humberstone A J, Porter CJH, Edward GA, Charman WN. Formulation Design and bioavailability assessment of lipidic self-emulsifying formulation of halofantrine. Int. J. Pharm. 1998; 167: 155-164. 
11. Reiss H. Entropy-induced dispersion of bulk liquids. J Colloid Interface Sci. 1975; 53(1): 61-70.

12. Nazzal S, Smalyukh II, Lavrentovich OD and Khan MA. Preparation and in vitro characterization of a eutectic based semisolid self-nanoemulsified drug delivery system (SNEDDS) of ubiquinone: mechanism and progress of emulsion formation. Int $\mathrm{J}$ Pharm. 2002; 235(1-2): 247-65.

13. Constantinides PP. Lipid microemulsions for improving drug dissolution and oral absorption: physical and biopharmaceutical aspects. Pharm Res. 1995; 12(11): 1561-72.

14. Dabros $\mathrm{T}$, Yeung $\mathrm{A}$, Masliyah $\mathrm{J}$ and Czarnecki J. Emulsification through Area Contraction. J Colloid Interface Sci. 1999; 210(1): 222-4.

15. Wakerly MG, Pouton CW, Meakin BJ and Morton FS. Self-emulsification of vegetable oilnon-ionic surfactant mixtures. ACS Symp Series. 1986; 311: 242-55.

16. Rang MJ and Miller CA. Spontaneous emulsification of oils containing hydrocarbon, nonionic surfactant, and oleyl alcohol. J Colloid Interface Sci. 1999; 209(1): 179-92.

17. Rang MJ and Miller CA. Spontaneous emulsification of oils containing hydrocarbon, nonionic surfactant, and oleyl alcohol. J Colloid Interface Sci. 1999; 209(1): 179-92.

18. Ito YKT, Ishida M, Tawa $R$, Shibata N, Takada K Oral solid gentamicin preparation using emulsifier and adsorbent. J. Cont. Rel. 2005; 105: 23-31.

19. Nazzal S, Khan MA, Controlled release of a self-emulsifying formulation from a tablet dosage form: stability assessment and optimization of some processing parameters. Int. J. Pharm. 2006; 315: 110-121.

20. Verreck G. Brewster ME. Melt extrusion-based dosage forms: excipients and processing conditions for pharmaceutical formulations. Bull. Tech. Gattefosse, 2004; 97: 85-95.

21. Bamba J, Cave G, Bensouda Y, Tchoreloff P, Pulsieux F, Couarrraze G. Cryoprotection of emulsions in freeze-drying: freezing process analysis. Drug Dev. Ind. Pharm. 1995; 21 : $1749-1760$. 